\title{
Zweierlei Staatsoberhaupt
}

Christoph Möllers

2012-06-21T15:21:42

Zwei Ereignisse, der Staatsbesuch des Bundespräsidenten in Israel und das Thronjubiläum der Königin von England, geben Anlass über die Funktion von Staatsoberhäuptern nachzudenken, einer Funktion, die ja nicht selten (zumal angesichts hiesiger präsidialer Malaisen) in Frage gestellt wird. Um das Ergebnis vorwegzunehmen: Nicht nur können Staatsoberhäupter auch heute noch eine Funktion erfüllen, sie können auch ganz unterschiedliche Funktionen erfüllen und gerade letztere, nur historisch oder vergleichend zu gewinnende Einsicht sollte uns vor zu allgemeinen Thesen über die Nutzlosigkeit dieses oder anderer Ämter warnen.

Das Thronjubiläum bot dem Vereinigten Königreich die Gelegenheit, sich als Nation in einem großen klassenlosen allgemeinen Fest zu sammeln. Das gelang natürlich wegen der besonderen Ausstrahlung der Gefeierten unter den Bedingungen einer alten konstitutionellen Monarchie, aber dies allein reicht nicht hin, um das freudige Ereignis zu erklären. Hinzutreten musste auch die Bereitschaft der "Subjects" , sich auf ein solches Ereignis einzulassen. Charakterisisch scheint mir, dass es in dieser Feier nicht darum ging, was die Briten "wirklich" verband, dies ist in der homogenitäts- und konsensfixierten deutschen Tradition die oft gestellte falsche Frage - es ging vielmehr darum, was sie nicht trennt. Es ging um die Bereitschaft, Unterschiede hintanzustellen, um unter einem Symbol zu feiern. Genau das bleibt die Errungenschaft des demokratischen Nationalstaats, eine Ebene der NichtUnterschiedlichkeit zu stiften, ohne Unterschiede totalitär aufheben zu wollen.

Der Besuch von Bundespräsident Gauck in Israel bleibt vor allem wegen der Korrektur in Erinnerung, die er einer Formulierung der Bundeskanzlerin gab, welche die Existenz Israels zum Teil der deutschen Staatsräson erklärt hatte. Aus Gaucks vorsichtiger Modifikation wurde schnell ein politischer Gegensatz konstruiert, an den zu glaben schwer fällt. Vielmehr könnte hier eine entstehende Arbeitsteilung zu erkennen sein, in der eine stets unter Druck stehende Regierungschefin kurzfristig Antworten geben muss, während ein sprachbewusstes Staatsoberhaupt eine reflektierte Neuformulierung nicht gegen diese, sondern mir ihr entwickeln kann. Solche Arbeitsteilungen kennen wir aus bikameralen Parlamenten, klassischerweise zwischen dem ruhig deliberierenden Senat und dem hektisch politisierten Repräsentantenhaus. Sie muss nicht auf diese beschränkt sein. Sie würde beide Ämter aus einem künstlichen Gegensatz ziehen und den Bundespräsidenten davon befreien, sich gegen den politischen Prozess profilieren zu müssen - oder unprofiliert zu bleiben.

Carl Schmitts berüchtigte Kritik des Parlamentarismus behauptete, dass das Parlament als Institution des liberalen Konstitutionalismus des 19. Jahrhunderts seine Rolle in der Massendemokratie des 20. Jahrhunderts verlieren würde. Sie baute auf die stilschweigende Annahme, dass Institutionen nicht ihre Funktionen ändern könnten. Nichts spricht dafür, dass dies stimmt. Die monarchische Herkunft 
des Bundespräsidentenamtes bietet so wenig ein Argument gegen dieses wie die Funktion der Monarchie in Britannien gleich geblieben wäre. Verfassungstheorie und Verfassungsvergleich bedürfen allerdings eines Sinns für institutionellen Funktionswandel und Ungleichzeitigkeiten, um dies beschreiben zu können. 